\title{
Conservação dos bens culturais móveis em papel: termos-chave em português e seus equivalentes em russo
}

\section{Book and Paper conservation: key terms in Portuguese and their equivalents in Russian}

Denise Regina de Sales*

Marina Canofre ${ }^{* *}$

\footnotetext{
"Prof. ${ }^{a}$ Dr. ${ }^{a}$ do Setor de Russo do Departamento de Línguas Modernas no Instituto de Letras, Universidade Federal do Rio Grande do Sul. E-mail: denise.sales@ufrgs.br.

** Graduanda do Bacharelado em Tradução do Instituto de Letras da Universidade Federal do Rio Grande do Sul. E-mail: canofremarina@gmail.com
} 
Resumo: Este artigo visa descrever e analisar questões de Terminologia e Tradução do par linguístico português-russo relacionadas à pesquisa terminológica "A Linguagem do Patrimônio Cultural Brasileiro: Conservação dos Bens Culturais Móveis”. A pesquisa visava descrever práticas textuais da área, explicitando sua organização conceitual e terminológica, e incluiu: a compilação de corpora em português, espanhol, francês, inglês, italiano e russo; a identificação de termos em português; a busca de equivalentes para esses termos nas línguas citadas; e a criação de uma base terminológica on-line multilíngue de acesso gratuito. As investigações basearam-se nos pressupostos da Teoria Comunicativa da Terminologia (TCT); na noção de equivalência tradutória de Hurtado Albir; nos preceitos metodológicos da Linguística de corpus; e em trabalhos anteriores do Projeto Terminológico Cone Sul (Termisul).

Palavras-chave: Terminologia; Tradução; Língua russa; Língua portuguesa; Conservação dos Bens Culturais Móveis.

Abstract: This work aims to describe and analyze issues concerning Portuguese and Russian translation related to the project "The Language of Cultural Brazilian Heritage: Book and Paper conservation". The research focused on describing textual practices of this area and explained its conceptual and terminological organization. A compilation of corpora was done in Portuguese, Spanish, French, English, Italian and Russian. Then the terms in Portuguese texts were identified, and their equivalents were searched in the mentioned languages. The final product is a multilingual online terminology dataset with free access. The investigations were based on the assumptions of the Communicative Theory of Terminology (TCT); in Hurtado Albir's notion of translation equivalence; in the methodological precepts of corpus linguistics; and in previous works of the Projeto Terminológico Cone Sul (Termisul).

Keywords: Terminology; Translation; Russian language; Portuguese language; Conservation of movable cultural goods

Resumen: Este artículo tiene como objetivo describir y analizar problemas de traducción de las lenguas portuguesa y rusa relacionados a la investigación $A$ Linguagem do Patrimônio Cultural Brasileiro: Conservação dos Bens Culturais Móveis. Dicha investigación aspiraba describir prácticas textuales del área, explicitando su organización conceptual y terminológica, e incluyó: compilación de corpus para el portugués, español, francés, inglés, italiano y ruso; identificación de términos en portugués; búsqueda de equivalentes en las referidas lenguas; y creación de una base terminológica en línea, multilingüe y de acceso libre. La investigación se basó en la Teoría Comunicativa de la Terminología (TCT), y en la noción de equivalencia traductora de Hurtado Albir. Además, se fundamentó en los principios de la Lingüística de Corpus y en trabajos del Projeto Terminológico Cone Sul (Termisul). ${ }^{1}$

Palabras-clave: Terminología; Traducción; Ruso; Portugués; Conservación de los Bienes Culturales Muebles.

\section{Introdução}

\footnotetext{
${ }^{1}$ Agradecemos a Mariana Carpinejar pela tradução para o espanhol.

TradTerm, São Paulo, v.36, dezembro/2020, p. 102-127

www.revistas.usp.br/tradterm
} 
A interface entre Terminologia e Tradução tem rendido muitas investigações científicas e artigos acadêmicos e mostra-se fecunda, em cada campo do conhecimento, para ampliar as discussões acerca dos textos especializados. Neste artigo apresentamos e discutimos questões de terminologia e tradução do par linguístico português-russo relacionadas à pesquisa terminológica "A Linguagem do Patrimônio Cultural Brasileiro: Conservação dos Bens Culturais Móveis", com duração de 2016 a 2019, no Projeto Terminológico Cone Sul (Termisul) ${ }^{2}$, na Universidade Federal do Rio Grande do Sul (UFRGS), em parceria com o Curso de Conservação e Restauração de Bens Móveis da Universidade Federal de Pelotas (UFPEL).

O objetivo dessas pesquisas é descrever práticas textuais da área da Conservação de Bens Culturais Móveis em suporte papel, explicitando sua organização conceitual e terminológica. Inicialmente foram compilados corpora em português, espanhol, francês, inglês, italiano e russo de acordo com os preceitos metodológicos da Linguística de Corpus. Os textos, buscados na web em sites de universidades, órgãos governamentais, bibliotecas, museus e similares, passaram pelas fases de limpeza, armazenamento e catalogação. Do corpus de língua portuguesa, foram extraídos os termos da área, para os quais foram feitas fichas terminológicas. Na sequência, as equipes das outras línguas cuidaram da busca dos equivalentes e da elaboração de suas respectivas fichas.

Nesse contexto, o trabalho com o russo seguiu, desde o início, as orientações gerais do projeto, além de contar com algumas etapas específicas em função das peculiaridades da língua. 0 corpus de língua russa do Termisul na área da Conservação de Bens Culturais Móveis em suporte papel é composto por 64 textos. Os gêneros dos textos abrangem manuais e guias destinados a funcionários, apostilas e manuais destinados a estudantes, relatórios de programas de conservação e restauração, teses, dissertações, resumos expandidos e artigos de periódicos.

${ }^{2}$ Criado em 1991 no Instituto de Letras da Universidade Federal do Rio Grande do Sul (UFRGS). Tem desenvolvido pesquisas no campo da Terminologia, com destaque para a interface com a Tradução. Entre os produtos dessas pesquisas estão dicionários e glossários (por exemplo, o Dicionário de Direito Ambiental: terminologia das leis do meio ambiente, de 1998; e o Glossário Multilíngue de Direito Ambiental Internacional: terminologia dos tratados, de 2004) e bases terminológicas de acesso on-line gratuito (por exemplo, Base de Combinatórias Léxicas Especializadas da linguagem legal). Mais informações e acesso às bases no site http://www.ufrgs.br/termisul/

TradTerm, São Paulo, v.36, dezembro/2020, p. 102-127

www.revistas.usp.br/tradterm 
Quadro 1. Caracterização ${ }^{3}$ do corpus inicial ${ }^{4}$

\begin{tabular}{|l|l|}
\hline Tamanho & $\sim 650$ mil palavras em 64 textos \\
\hline Formato & $\begin{array}{l}\text { Publicados em formato digital, baixados da Internet e } \\
\text { convertidos para .txt }\end{array}$ \\
\hline Origem & $\begin{array}{l}\text { Sites de universidades, órgãos da estrutura estatal de } \\
\text { Conservação e Restauração, bibliotecas, museus, instituições } \\
\text { públicas e privadas que formam os profissionais da área }\end{array}$ \\
\hline Autores & $\begin{array}{l}\text { Pesquisadores, professores, profissionais da área, servidores } \\
\text { públicos de órgãos da Conservação e Restauração }\end{array}$ \\
\hline Factualidade & $\begin{array}{l}\text { Temas de interesse da área (procedimentos e materiais } \\
\text { aplicados na conservação e restauração, relatos de processos de } \\
\text { restauração, relatórios de programas de conservação etc.) }\end{array}$ \\
\hline Tecnicidade & $\begin{array}{l}\text { Alto nível de especialização (por especialistas e para } \\
\text { especialistas) e médio nível de especialização (por especialistas } \\
\text { para aprendizes) }\end{array}$ \\
\hline Público & Especialistas e semi-especialistas \\
\hline Intenção & Informativa, didática e instrutiva \\
\hline Cenário & Uso acadêmico e institucional \\
\hline Temática & Restauração e Conservação de Bens Móveis em suporte papel \\
\hline
\end{tabular}

Fonte: As autoras.

A pesquisa dos textos na internet foi feita em 2017 e 2018. As palavras de busca em português foram assim traduzidas para a língua russa: документ [dokumient, documento] ${ }^{5}$, документация [dokumentatsia, documentação], сохранение [sokhranienie, conservação], бумага [bumaga, papel], памятник [pamiatnik, patrimônio], реставрация [restavratsia, restauração], ремонт [remont, restauro]. A essas primeiras palavras de busca somaram-se depois: консервация [konservatsia, conservação] е наследue [nasliedie, patrimônio], que encontramos com frequência nos primeiros textos baixados.

\footnotetext{
${ }^{3}$ Usamos como modelo a tabela apresentada em http://www.ufrgs.br/termisul/legis.php para a base Legis do Projeto Terminológico Cone Sul (Termisul).

${ }^{4} \mathrm{Na}$ etapa de busca de contextos fora do corpus (ruPP), selecionamos e baixamos outros textos relevantes que passaram a integrar o corpus ampliado (ru2PP).

${ }^{5}$ Neste artigo registramos os equivalentes em russo dos termos e das Unidades Fraseológicas Eventivas (UFEs) da seguinte forma: na primeira ocorrência, a palavra russa, seguida da transliteração no alfabeto latino e da tradução entre colchetes; nas ocorrências seguintes, a palavra transliterada. As traduções são aquelas dadas por VoINOVA ET AL (1989).
} 
Todos os textos foram listados em um catálogo, que, no caso da língua russa, apresenta seis campos: o código do arquivo no corpus; o nome do autor, o título do texto e a fonte em língua russa, os mesmos itens anteriores transliterados, os mesmos itens anteriores em língua portuguesa; a URL do texto; e a data de acesso.

Quadro 2. Trecho do catálogo de textos do corpus de língua russa.

\begin{tabular}{|c|c|c|c|c|c|}
\hline Código & $\begin{array}{l}\text { Autor, título, fonte } \\
\text { (em língua russa) }\end{array}$ & $\begin{array}{l}\text { Autor, título, fonte } \\
\text { (transliterados no } \\
\text { alfabeto latino) }\end{array}$ & $\begin{array}{l}\text { Autor, título, fonte (traduzidos } \\
\text { para a língua portuguesa) }\end{array}$ & $\begin{array}{l}\text { Disponível } \\
\text { Em }\end{array}$ & Acesso em \\
\hline ruPP015 & $\begin{array}{l}\text { ГОЛЫШЕВА, Е. В. } \\
\text { Консервация документов } \\
\text { на бумажных носителях. }\end{array}$ & $\begin{array}{l}\text { GOLYCHEVA, IE. V. } \\
\text { Konservatsia dokumientov } \\
\text { na bumajnykh } \\
\text { nossiteliakh. }\end{array}$ & $\begin{array}{l}\text { GOLYCHEVA, IE. V. Conservação } \\
\text { de documentos em suporte } \\
\text { papel. }\end{array}$ & $\begin{array}{l}\text { https://bit.l } \\
\text { y/2XYjHPq }\end{array}$ & $19 / 09 / 2017$ \\
\hline ruPP016 & $\begin{array}{l}\text { МЕДВЕДЕВА, Л. А.; } \\
\text { СТАРЦЕВА, Т. А. } \\
\text { Справочник сельского } \\
\text { библиотекаря. }\end{array}$ & $\begin{array}{l}\text { MIEDVIEDIEVA, L. A.; } \\
\text { STARTSIEVA, T. A. } \\
\text { Spravotchnik sielskogo } \\
\text { bibliotekaria. }\end{array}$ & $\begin{array}{l}\text { MIEDVIEDIEVA, L. A. } \\
\text { STARTSIEVA, T. A. } \\
\text { Guia do bibliotecário rural. }\end{array}$ & $\begin{array}{l}\text { https://bit.l } \\
\text { y/2y0f7AP }\end{array}$ & $19 / 09 / 2017$ \\
\hline ruPP017 & $\begin{array}{l}\text { CЕМЕНОВА, Л. В. } \\
\text { О консервации } \\
\text { библиотечных фондов. }\end{array}$ & $\begin{array}{l}\text { SIEMIENOVA, L. V. } \\
\text { O konsiervatsii } \\
\text { bibliotietchnykh fondov. }\end{array}$ & $\begin{array}{l}\text { SIEMIENOVA, L. V. } \\
\text { Sobre a conservação dos acervos } \\
\text { de bibliotecas. }\end{array}$ & $\begin{array}{l}\text { https://bit.l } \\
\text { y/2MJQi5N }\end{array}$ & $19 / 09 / 2017$ \\
\hline
\end{tabular}

Fonte: as autoras.

$\mathrm{Na}$ fase de busca de equivalentes em fontes externas, localizamos outros textos da área. Alguns deles se mostraram muito produtivos para as buscas finais e, por isso, foram incluídos em um segundo corpus, codificado como ru2PP. Os equivalentes estabelecidos foram inseridos na base on-line, juntamente com o seu contexto. No campo "Entrada"6, além do equivalente do termo ou UFE em língua russa, inserimos a sua transliteração para o alfabeto latino. A entrada do equivalente de "papel", por exemplo, apresenta-se assim: бумага [bumaga].

\section{Terminologia e Tradução}

Este artigo baseia-se nos pressupostos da Teoria Comunicativa da Terminologia (TCT), que prioriza a multidimensionalidade da unidade de conhecimento especializado (CABRÉ 1999), e na noção de equivalência tradutória de Hurtado Albir, que define a

\footnotetext{
${ }^{6} \mathrm{Na}$ base, os termos são apresentados no campo "Entrada”, seguido dos campos “Contexto", "Outras formas", "Ver também" e "Equivalentes".
}

TradTerm, São Paulo, v.36, dezembro/2020, p. 102-127 www.revistas.usp.br/tradterm 
tradução como um ato de comunicação, operação textual e atividade cognitiva (HURTAdo AlBiR 2001). Além disso, damos prosseguimento a quase trinta anos de pesquisas do grupo Termisul, que tem produzido referências próprias, cientificamente consistentes, relativas à terminologia de várias áreas do conhecimento especializado.

A TCT considera como termos as unidades da língua natural que representam e transmitem conhecimento especializado. Essas unidades devem ser estudadas no local em que ocorrem e funcionam, ou seja, nos próprios textos. 0 estudo e a descrição das características comunicativas dos textos é um dos passos do processo de reconhecimento e avaliação dos termos ou outras unidades que também são objeto da Terminologia, como, por exemplo, as Unidades Fraseológicas Especializadas Eventivas (UFE eventivas), caracterizadas como sintagmas nominais ou verbais. ${ }^{7}$ A variação é reconhecida como um fenômeno da Terminologia, uma vez que o processo de comunicação implica em formas alternativas de denominação de um conceito (sinonímia) ou em abertura para mais de um sentido (polissemia).

Como projeto que abriga estudos terminológicos multilíngues, o Termisul tem se baseado na definição de tradução de Hurtado Albir para construção do referencial teórico nesse campo. A tradução é considerada como processo de interpretação e comunicação que envolve reformular um texto em uma língua com recursos de outra língua. Esse processo sempre acontece em determinado contexto social e tem uma finalidade definida.

A interface entre Tradução e Terminologia tem sido tratada em projetos, artigos e trabalhos de graduandos, pós-graduandos, pesquisadores e docentes do Termisul. Bevilacqua e Kilian ressaltam a importância de se considerar, no processo tradutório, "as características textuais, tanto internas quanto externas, aspectos referentes ao gênero textual e outros aspectos linguísticos", a fim de respeitar o conjunto do "sentido expresso no texto" e não apenas o sentido de palavras e frases isoladas (2017: 1711). As autoras listam dois pontos principais de interseção entre Tradução e Terminologia,

\footnotetext{
${ }^{7}$ Para uma caracterização detalhada das UFEs eventivas, ver Bevilacqua (2004). Um estudo aprofundado das UFEs eventivas da área da Conservação de Bens Culturais móveis em suporte papel pode ser encontrado em ARCOS, 2019.
}

TradTerm, São Paulo, v.36, dezembro/2020, p. 102-127 www.revistas.usp.br/tradterm 
áreas interdisciplinares e transdisciplinares, que consideram o texto e a situação comunicativa como fatores fundamentais.

Bevilacqua (2004) aprofundou-se no estudo das Unidades Fraseológicas Especializadas Eventivas - sintagmas formados por um núcleo terminológico (NT) de categoria nominal e um núcleo eventivo (NE) de categoria verbal ou derivado de verbo (consumir energía, consumo de energía, energía consumida). A partir desse estudo, Waquil (2013) investigou a tradução de textos especializados, tendo concluído que "a relação de equivalência estabelecida entre UFEs é relativa, flexível e dinâmica" (WAQUIL 2013: 151). Isso significa que é importante analisar o contexto de utilização da unidade (pesquisa com corpora), que o tradutor tem liberdade para rearranjar a estrutura em que se insere o equivalente, considerando a mensagem a ser transposta, e que as unidades podem ter mais de um equivalente em outras línguas.

Arcos (2019) retomou a noção de UFEs eventivas para identificar e analisar essas unidades no corpus em língua portuguesa da área de Conservação e Restauração de bens culturais móveis em suporte papel. As suas conclusões a respeito dos NEs “conservação", “preservação” e "restauração" (ARcos 2019: 104), caracterizados como termos-chave da área por Bevilacqua, Bojanoski e Michelon (2017), são confrontadas aqui com os resultados da análise dos equivalentes em língua russa.

\section{Termos e UFEs em português e seus equivalentes em russo}

Para análise neste artigo escolhemos três termos da área da Conservação e Restauração em português - "preservação", "restauração" e "conservação" - e seus equivalentes em russo. Essa escolha foi feita, em primeiro lugar, porque as questões de Tradução e Terminologia que eles suscitaram são representativas do conjunto dos termos investigados. Em segundo lugar, porque são termos basilares da área, pois “indicam ações fundamentais, específicas e diferenciadas, mas, em sua essência interdependentes, em relação aos bens culturais" e "sua análise permite delinear questões importantes para compreender a área de conhecimento em estudo" 
(BEVILACQUA; BoJANOSKI; MICHELON 2017: 445). Em terceiro lugar, porque, na combinação com os núcleos terminológicos (NT) de "maior produtividade fraseológica no corpus" em português - "acervo", “documento", “livro", “obra” e "papel” -, aparecem entre os cinco núcleos nominais (NN) que expressam "ações mais amplas da área, sendo usados como hiperônimos para referir-se, em diversas ocasiões, a outros processos menores e subordinados" (ARCOs: 2019). Em quarto lugar, porque é grande o número de ocorrências dos equivalentes no corpus em língua russa (Quadro 4).

Quadro 4. Termos-chave em português e seus equivalentes em russo.

\begin{tabular}{|c|c|c|c|}
\hline $\begin{array}{l}\text { Termos-chave em } \\
\text { português }\end{array}$ & \multicolumn{3}{|c|}{$\begin{array}{l}\text { Equivalentes em russo/ocorrências no catálogo/ocorrências no } \\
\text { corpus }\end{array}$} \\
\hline Preservação & $\begin{array}{l}\text { Сохранение } \\
\text { [sokhranenie] }\end{array}$ & 11 & 1.333 \\
\hline Restauração & $\begin{array}{l}\text { Реставрация } \\
\text { [restavratsia] }\end{array}$ & 19 & 2.213 \\
\hline Conservação & $\begin{array}{l}\text { Консервация } \\
\text { [konservatsia] }\end{array}$ & 12 & 1.230 \\
\hline
\end{tabular}

Fonte: As autoras

A análise dos três termos será apresentada em sua relação com as etapas de realização dos projetos de pesquisa: seleção e preparação dos textos para compilação do corpus; catalogação dos textos; busca de equivalentes em russo para os termos em português e busca de equivalentes em russo para UFEs em português.

Para melhor compreensão da terminologia da Conservação e Restauração na Rússia, a seguir, descreveremos brevemente a situação da normatização da área. Ressaltamos que não recolhemos textos de leis e normas governamentais para compor o corpus, mas muitos dos textos utilizados citam trechos da regulamentação estatal, seja para indicá-las como referência nas tarefas cotidianas e no planejamento geral, seja para criticar aspectos polêmicos das decisões tomadas pelos órgãos reguladores.

Posteriormente passaremos à análise dos equivalentes em russo para os três termos selecionados. 


\subsection{Normatização terminológica da área de Conservação e Restauração na Rússia}

Na Rússia a terminologia da área de Conservação e Restauração de documentos em papel, pergaminho e couro rege-se pelo GOST ${ }^{8}$ 7.48-2002, aprovado pelo Conselho Intergovernamental de Padronização, Metodologia e Certificação, constituído por representantes do Azerbaijão, Armênia, Belorrússia, Cazaquistão, Quirguízia, Moldova, Rússia, Tajiquistão, Turcomenistão, Uzbequistão e Ucrânia, além da Federação Russa. Esse documento de 23 páginas, elaborado por representantes de bibliotecas russas e de um Comitê Técnico Intergovernamental, compõe-se de oito itens: 1) Campo de aplicação, 2) Conceitos gerais, 3) Danificação dos documentos, 4) Regime de manutenção dos documentos, 5) Estabilização dos documentos, 6) Restauração dos documentos, 7) Preparação de cópias dos documentos e 8) Características dos documentos. Ele contém ainda duas listas em ordem alfabética de termos em língua russa e de termos em língua inglesa. Obviamente, sendo um documento de padronização, determina que os termos ali definidos devem ser usados por "todo tipo de biblioteca e órgão de informação técnico-científico" em suas "documentações e publicações" e proíbe a "utilização de termos sinônimos" alternativos (GOST 7.48-2002: 4). Outros documentos de padronização de áreas correlatas, como por exemplo, da Arquivologia e da Biblioteconomia, também fazem referência a termos da Conservação e Restauração. Dois deles, usados na parte da análise, são apresentados no quadro a seguir.

\begin{tabular}{|l|l|l|}
\hline GOST & ESCOPO & SEÇÕES \\
\hline $7.87-2003$ & $\begin{array}{l}\text { LIVROS RAROS } \\
\text { requisitos gerais }\end{array}$ & $\begin{array}{l}\text { 1) Área de aplicação; 2) Referências normativas; 3) Termos e } \\
\text { definições; 4) Tipos de livros raros; 5) Categorias de livros } \\
\text { raros; 6) Critérios e sinais de identificação de livros raros; 7) } \\
\text { Descrição de livros raros; 8) Inventário de livros raros; 9) } \\
\text { Guarda governamental de livros raros; 10) Uso de livros raros. }\end{array}$ \\
\hline $7.50-2002$ & $\begin{array}{l}\text { CONSERVAÇÃO DE Área de aplicação; 2) Referências normativas; 3) } \\
\text { DOCUMENTOS }\end{array}$ & \begin{tabular}{l} 
Considerações gerais; 4) Regime de guarda dos documentos; \\
\hline
\end{tabular} \\
\hline
\end{tabular}

8 Transliteração de ГОСТ - Межгосударственный Стандарт [Padrão interestatal]. A padronização proposta no GOST 7.48-2002 foi adotada pelos países da CEI (Comunidade de Estados Independentes), organização fundada em 1991 e que abriga onze das repúblicas que compunham a URSS.

TradTerm, São Paulo, v.36, dezembro/2020, p. 102-127 www. revistas.usp.br/tradterm 
Quadro 3. Normas russas relativas à área de Conservação e Preservação. Elaborado pelas autoras.

As características dos GOSTs indicam o caráter interdisciplinar da Conservação e Restauração, confirmando as observações de Bojanoski para a língua portuguesa:

Se no século XVIII se confundia com o fazer artístico, no século XX, especialmente em decorrência das imensas destruições ocasionadas pelas duas grandes guerras no patrimônio cultural europeu, a Conservação alcançou um desenvolvimento maior. Por sua natureza, é uma área inerentemente interdisciplinar, que se estrutura a partir da articulação entre os conhecimentos técnico, humanístico e científico. Como uma área inserida no campo da preservação patrimonial, mobiliza conhecimentos de vários campos de saber, que convergem para a salvaguarda dos bens culturais nos seus vários aspectos. (2018: 16)

No corpus, encontram-se textos que confirmam a existência, na Rússia, de uma realidade da prática e teoria da Conservação e Restauração semelhante à do Brasil. Os bens culturais em suporte papel são guardados, preservados, conservados e restaurados em locais diversos: "não apenas em arquivos, mas também em bibliotecas, museus, setores de universidades e academias" (OLBREKHT 2016) ${ }^{9}$ e cada uma dessas instituições tem particularidades no modo como realiza a conservação e a restauração. Consequentemente, questões relativas à preservação desses bens são investigadas por pesquisadores arquivistas, biólogos, químicos etc. E as referências dos trabalhos acadêmicos incluem títulos de áreas afins - museologia, arquivologia, biblioteconomia.

Os programas governamentais criados recentemente também afetam o panorama terminológico da área. Em 2000, foi criado o primeiro Programa Nacional de Preservação dos Acervos Bibliográficos da Federação Russa (2000-2010), seguido do Programa Russo de Preservação dos Acervos Bibliográficos da Federação Russa (2011-

\footnotetext{
9 Em russo:[...] “не только в архивах, но и в библиотеках, музеях, академических и вузовских подразделениях". Texto ruPP030, dissertação defendida em 2016 por P. S. Olbrekht pelo programa de Ciência da Documentação e Arquivologia da Universidade Federal Pedagógico-Profissional da cidade de Ekaterinburg.
} 
2020), baseados nas noções da Federação Internacional de Associações e Instituições Bibliotecárias.

Outro fator que afeta a constituição terminológica é a influência estrangeira, os contatos com outros pesquisadores e a necessidade de comunicação internacional. No corpus russo encontramos menções a textos da Organização das Nações Unidas para a Educação, a Ciência e a Cultura (UNESCO), que tem patrocinado programas de Conservação e Restauração na Rússia. Sendo o russo uma das seis línguas oficiais da Organização das Nações Unidas (ONU), juntamente com o árabe, chinês, espanhol, francês e inglês, podemos supor que os termos usados pela ONU sejam adotados pelos profissionais envolvidos na concretização desses programas.

Nesse contexto, a existência de documentos normativos não garante uniformidade dos termos - como já nos diz a TCT - e, nas situações reais de uso mostradas pelos textos do corpus em língua russa, observamos que, inclusive em textos recentes, portanto posteriores à publicação do último GOST da área, não há a rigorosa uniformidade terminológica pregada nas normas do governo; as variações dependem do tipo de publicação e dos órgãos aos quais ela está vinculada. Além disso, há questionamentos a respeito das premissas dos órgãos reguladores na elaboração de seus documentos. A falta de consenso nesse aspecto faz com que determinados grupos de pesquisadores façam questão de utilizar os termos que consideram mais adequados.

Confirmamos, portanto, nos projetos sobre a terminologia da Conservação e Restauração, a presença das variações, como apontado em outros trabalhos do Termisul, como aqueles sobre a legislação ambiental, em contraposição às tentativas de normatização.

Os manuais de redação legislativa de línguas e sistemas jurídicos diversos desaprovam a variação lexical no texto da lei por considerarem sua utilização um obstáculo a clareza, a precisão e a univocidade. Não obstante, combinatórias variantes foram encontradas no nosso corpus da pesquisa, constituído por recortes da legislação ambiental do Brasil, Alemanha, Argentina, Canadá, Estados Unidos, Itália, França, Paraguai e Uruguai. (MACIEL; REUILLARD 2015) 


\subsection{Termos-chave da área de Conservação e Restauração}

Os dados apresentados aqui foram acumulados durante as etapas de trabalho da equipe de língua russa nos projetos do Termisul relativos à terminologia da área da Conservação e Restauração, sobretudo nestas três: 1) tradução do catálogo de textos, 2) busca de equivalentes para os termos e 3) busca de equivalentes para as UFEs eventivas.

$\mathrm{Na}$ situação de tradução do catálogo, estávamos diante dos títulos dos 64 textos do corpus russo, no início do projeto. Em alguns dos títulos, obviamente, apareciam as palavras usadas na busca na web. Para elas, tínhamos a tradução inicial feita pela equipe de língua russa com base em dicionários bilíngues. Em alguns casos, essa tradução foi confirmada como uma solução satisfatória. Докуменm [dokumient] era o equivalente do termo "documento" e assim continuou até o final do projeto. Em alguns casos, porém, outros candidatos mostraram-se mais adequados e fizemos, portanto, alguma mudança posterior. A palavra de busca "conservação", por exemplo, tinha sido traduzida como сохранение [sokhranenie; conservação, manutenção] e, juntamente com бумага [bumaga, papel], gerou resultados muito produtivos na localização de textos da área estudada. Entretanto, quando utilizamos o recurso Concordance do software AntConc ${ }^{10}$, identificamos que sokhranienie com frequência aparecia junto da palavra консервация [konservatsia, conservação]. Qual seria então o equivalente russo para o termo "conservação" - konsiervatsia, um estrangeirismo que consta do Dicionário histórico de galicismos da língua russa, ou sokhranienie, cuja etimologia é eslava?

A pesquisa para identificação de equivalentes para os termos e, posteriormente, para as UFEs ampliaram a nossa compreensão do texto especializado russo. É o que apresentaremos a seguir nos três exemplos selecionados.

${ }^{10}$ Disponível em <http://www.laurenceanthony.net/software/antconc/>.

TradTerm, São Paulo, v.36, dezembro/2020, p. 102-127 www.revistas.usp.br/tradterm 


\subsubsection{Conservação, sokhranenie e konservatsia}

"Conservação" foi uma das palavras de busca de textos em português para o corpus. Quando passamos à pesquisa em fontes russas, testamos sokhranenie como equivalente de "conservação". No dicionário russo-português Voinova, no contexto da língua geral, as traduções para sokhranenie são: conservação, manutenção, salvaguarda. No dicionário russo Uchakov, as acepções do substantivo são: ato, processo ou efeito de conservar, guardar. $E$ as acepções do verbo de mesma raiz, сохранять/сохранить [sokhraniat/sokhranit]: guardar, resguardar, cuidar, não permitir que desapareça; proteger de danos. Etimologicamente, ambos têm origem eslava. Os resultados das buscas na web pela palavra sokhranenie geraram resultados satisfatórios tanto em quantidade de textos quanto em adequação dos textos à área estudada.

Entretanto, nos textos baixados, muitas vezes encontramos konservatsia ao lado de sokhranenie. Daí a questão terminológica apresentada anteriormente. Além disso, na fase de tradução dos títulos do catálogo de textos russos, observamos que “conservação" não funcionava sempre como tradução para sokhranenie. No título do texto ruPP062, por exemplo, Превентивная консервация [konservatsia] музейных коллекций и ее роль в сохранении [sokhranenie] объектов культурного наследия [A conservação (konservatsia) preventiva das coleções de museus e o seu papel na conservação (sokhranenie) dos objetos do Patrimônio Cultural]. Não que essa tradução pareça incorreta; faz sentido falarmos em "conservação preventiva" das coleções de museus e "na conservação [que seria hiperônimo da "conservação preventiva"] dos objetos do Patrimônio". 0 trato com os termos, no entanto, nos deixou alertas para a questão do uso: por que, no texto russo, usaram dois termos diferentes nesse trecho?

No texto ruPP038, konservatsia vem seguida de um parêntese com o termo em latim, seguido de sokhranenie: As questões relacionadas ao estado de conservação [sokhrannost] física dos objetos guardados, inclusive em bibliotecas, reúnem-se sob a 
denominação geral de conservação [konservatsia] (do latim conservatio sokharanenie) ${ }^{11}$ (tradução nossa).

No recurso Concordance do software AntConc, confirmamos que sokhranienie aparece às vezes junto de konservatsia (não necessariamente nessa ordem). Daí nossa segunda questão terminológica: konservatsia e sokhranenie são usados em russo como variantes, como sinônimos?

Quadro 5. Exemplos de ocorrência de konservatsia e sokhranenia no corpus russo pelo recurso Concordance do software AntConc.

\begin{tabular}{|c|c|}
\hline Código & resultado do Concordance \\
\hline ruPP004 & $\begin{array}{l}\text { региональные центры консервации/сохранения библиотечных } \\
\text { фондов } \\
\text { [centros regionais de konservatsia/sokhranenie de acervos de } \\
\text { bibliotecas] }\end{array}$ \\
\hline ru & $\begin{array}{l}\text { «Консервация (сохранение) библиотечных фондов» } \\
\text { [“onservatsia }(\underline{\text { sokhranenie }}) \text { de acervos bibliográficos”] }\end{array}$ \\
\hline ruPP023 & $\begin{array}{l}\text { Использование современных методов консервации в сохранении } \\
\text { коллекций } \\
\text { [Utilização de métodos contemporâneos de konservatsia na sokhranenie } \\
\text { de coleções] }\end{array}$ \\
\hline ruPP024 & $\begin{array}{l}\text { «Проблемы сохранения, консервации и реставрации музейных } \\
\text { объектов» } \\
\text { [“Problemas da sokhranenie, konservatsia e restauração de objetos de } \\
\text { museus”] }\end{array}$ \\
\hline ruPP058 & $\begin{array}{l}\text { направление в работе центра консервации - сохранение } \\
\text { [a orientação no trabalho do centro de konservatsia é a sokhranenie] }\end{array}$ \\
\hline
\end{tabular}

Fonte: As autoras

Sokhranenie não aparece nas noções gerais do GOST 7.48-2002. Lá está registrada konservatsia dokumentov (com o equivalente de língua inglesa -

\footnotetext{
11 Em russo: Вопросы, связанные с физической сохранностью объектов хранения, в том числе и библиотек,
} объединяются под общим названием - консервация (от лат. conservatio - coхранение).

TradTerm, São Paulo, v.36, dezembro/2020, p. 102-127 www.revistas.usp.br/tradterm 
conservation - entre parênteses), seguida da definição: "обеспечение сохранности документов посредством режима хранения, стабилизации, реставрации и изготовления копии" [garantia do estado de conservação de documentos por meio do regime de guarda, estabilização, restauração e preparação de cópias].

No ruPP030, há uma crítica ao instrumento normativo federal GOST 7.48.2002 pelo fato de terem listado os termos da área e não terem incluído dokument [documento], embora uma prova de que esse é um termo da área seja justamente o fato de que essa palavra aparece na composição de outros termos como "estado de conservação do documento" e "danos ao documento". Além disso, há um questionamento sobre a ausência de um termo em russo para "preservation".

Em segundo lugar, falta o termo de língua inglesa preservation. Esse é um termo de significado amplo, que abrange conservação e tudo o que se faz na biblioteca para melhorar o estado do documento. No entanto, por não terem conseguido um equivalente em russo, não se justifica desprezarem termo tão básico. Enquanto não se forja solução melhor, conviria pelo menos deixar o "сохранение" [sokhranenie]. ${ }^{12}$ (tradução nossa)

Concluímos, portanto, que, embora na língua geral konservatsia e sokhranenie possam ser usadas como sinônimo, na amostra de uso real compilada, ou seja, no nosso corpus de língua russa, konservatsia é o equivalente de "conservação", e sokhranenie, o de "preservação". O título recém-citado foi traduzido assim: A conservação [konservatsia] preventiva das coleções de museus e o seu papel na preservação [sokhranenie] dos objetos do Patrimônio Cultural.

$\mathrm{Na}$ fase de busca de equivalentes para as UFEs eventivas, firmamos ainda mais essa posição. Observamos como o núcleo eventivo se comporta nos equivalentes para as UFEs eventivas formadas por "conservação" + núcleo terminológico. Arcos (2019: 104) analisa os núcleos eventivos "conservação", "preservação" e "restauração", a exemplo do que faz Bojanoski (2018: 106), como hiperônimos sujeitos à variação

12 Em russo: Во-вторых, отсутствует англоязычный термин preservation. Это термин широкого значения, охватывающий и консервацию, и все, что делается в библиотеке для улучшения состояния документов. Однако из-за того, что не сумели найти русский эквивалент, выбрасывать основополагающий термин недопустимо. Пока не придумано лучшего, следовало бы оставить и «сохранение».

TradTerm, São Paulo, v.36, dezembro/2020, p. 102-127 www.revistas.usp.br/tradterm 
terminológica. "Conservação" pode designar a área de conhecimento ou os procedimentos e processos que impedem a deterioração e degradação. Na base de dados terminológicos, isso se reflete em duas entradas.

“Conservação 1”, com o contexto

E, ao fazer uma reflexão sobre a área de conservação de documentos de arquivo, esta autora argumenta que se pode perceber uma mudança de paradigma na Arquivologia, que contribui para uma nova relação perante aos acervos: quando por um lado, a Arquivologia admitiu sua aproximação mais estreita com a Ciência da Informação, e por outro, quando reconheceu que a preservação documental insere-se num programa responsável de administração arquivística [...]. (ptPP142)

“Conservação 2", com o contexto

Segundo o Comitê de Conservação do Conselho Internacional de Museus, o conceito de conservação abrange "[...] todas aquelas medidas ou ações que tenham como objetivo a salvaguarda do patrimônio cultural tangível, assegurando sua acessibilidade às gerações atuais e futuras”, compreendendo "[...] a conservação preventiva, a conservação curativa e a restauração", sendo que "todas estas medidas e ações deverão respeitar o significado e as propriedades físicas do bem cultural em questão [...] (ptPP097)

Em russo, encontramos o mesmo comportamento do termo konservatsia, representado na base terminológica como equivalentes de "conservação 1" e “conservação 2",

\section{Konservatsia 1}

Em 1969, lu. P. Niukcha escreveu que a questão da conservação dos bens culturais e científicos desenvolveu-se tão detalhadamente em termos de conteúdo e volume que foi classificada como uma área de pesquisa científica independente, com sua própria história, quadros, bibliografias. Além disso, como qualquer ciência, a conservação de documentos deve ter todos os componentes necessários à pesquisa científica - conteúdo básico, objeto, objetivo, funções, estrutura, orientações básicas, metodologia e métodos de pesquisa. ${ }^{13}$ (ruPP038) (tradução nossa)

13 Em russo: В 1969 г. Ю.П. Нюкша писала, что вопрос консервации [konservatsia] культурных и научных ценностей настолько подробно разработан по содержанию и объему, что рассматривается как самостоятельный раздел научных исследований, имеющий свою историю, кадры,

TradTerm, São Paulo, v.36, dezembro/2020, p. 102-127 www. revistas.usp.br/tradterm 


\section{Konservatsia 2}

O objetivo principal da conservação do AB [acervo bibliográfico] consiste em garantir, por longo prazo, a proteção e defesa dos documentos em relação a ações indesejáveis do meio ambiente, por meio de procedimentos de prevenção, estabilização e recuperação, para a preservação do acervo bibliográfico como base do funcionamento da biblioteca em todas as etapas de sua formação e utilização. ${ }^{14}$ (ruPP038) (tradução nossa)

Além disso, pela busca no corpus, conseguimos estabelecer equivalentes para as UFEs eventivas em português formadas por "conservação” (konservatsia).

Quadro 7. Exemplos de UFEs eventivas compostas do núcleo eventivo “conservação” seguido de um núcleo terminológico.

\begin{tabular}{|c|c|}
\hline UFE eventiva em português & Equivalente em russo da UFE eventiva em português \\
\hline conservação de acervo & консервация фонда [konservatsia fonda] \\
\hline conservação de biblioteca & консервация библиотеки [konservatsia biblioteki] \\
\hline conservação de coleção & консервация коллекции [konservatsia kollektsii] \\
\hline $\begin{array}{ll}\text { conservação } & \text { de } \\
\text { documentos } & \end{array}$ & кодсервация документа [konservatsia dokumenta] \\
\hline conservação de livros & консервация книги [konservatsia knigui] \\
\hline conservação de obra & произведения [konservatsia \\
\hline conservação de suporte & консервация носителя [konservatsia nossitelia] \\
\hline
\end{tabular}

Fonte: As autoras

\subsubsection{Restauração e restavratsia}

библиографию. Более того, как любая наука консервация [konservatsia] документов должна иметь все необходимые компоненты научного исследования - основное содержание, объект и предмет, цель, функции, структуру, основные направления, методологию и методику исследования. (sublinhado e transliteração nossos)

$14 \mathrm{Em}$ russo: Основная цель консервации [konservatsia] БФ [библиотечного фонда] состоит в том, чтобы обеспечить долговременную безопасную защиту документов от неблагопрятных воздействии окружающей среды путем превентивных, стабилизационных и восстановительных мероприятий в целях сохранения [sokhranenie] библиотечного фонда как основы фуникионирования библиотеки на всех этапах его формирования и использования. 
Restavratsia é um estrangeirismo que, segundo o dicionário etimológico, chegou à língua russa pelo alemão restaurieren ou pelo francês restaurer. Noção semelhante é dada pela palavra de origem eslava восстановление [vosstanoblenie, recuperação, restauração, reconstituição], que ocorre no corpus (121 no Concordance), mas não é palavra-chave da área.

No GOST 7.48-2002, vosstanovlenie não aparece como termo, mas está presente nas definições dos termos. Por exemplo: “реставрация документа (restoration): восстановление эксплуатационных свойст, а также формы и внешнего вида документа" [restauração do documento (restoration): vosstanovlenie das características operacionais, assim como da forma e do aspecto externo do documento].

Portanto, nesse caso, temos uma situação diferente daquela observada com conservação, sokhranenie e konservatsia. Nos primeiros textos baixados, ocorria o termo restavratsia, que incluímos na lista de palavras de busca. Na tradução dos títulos do catálogo, optamos por "restauração" como equivalente de restavratsia e todos os resultados tradutórios foram satisfatórios, como, por exemplo, no ruPP001 “Актуальные вопросы реставрации и сохранения памятников истории и культуры”, que foi traduzido como "Questões atuais da restauração e preservação de bens da história e da cultura". No estabelecimento de equivalentes para as UFEs compostas por "restauração", essa solução também funcionou bem. Alguns exemplos: restauração de biblioteca - bibliotetchnaia restavratsia; restauração de documento restavratsia dokumenta, restauração de obra - restavratsia proizvedenia.

\subsubsection{Preservação, predokhranenie, cokhranenie e защuma [zaschita, proteção]}

O estrangeirismo презервация [prezervatsia ${ }^{15}$ ] está registrado em vários dicionários russos, dos quais trazemos dois exemplos. No Dicionário de palavras

\footnotetext{
${ }^{15}$ Não existe esse verbete no Dicionário russo-português adotado para este trabalho.
}

TradTerm, São Paulo, v.36, dezembro/2020, p. 102-127 www.revistas.usp.br/tradterm 
estrangeiras da língua russa ${ }^{16}$ : (do latim) предохранение [predokhranenie, preservação, resguardo, proteção]. No Dicionário histórico de galicismos da língua russa ${ }^{17}$, (pelo francês préservation, do latim praeservatio) предохранение [predokhranenie], профилактика [profilaktika, profilaxia]. No dicionário Uchakov, a acepção de preservatsia também é predokhranenie; além disso, ele traz a informação de que a palavra é usada na linguagem formal.

Entretanto, esse estrangeirismo não ocorre nos textos do corpus de língua russa do Termisul. Por outro lado, o termo preservation em inglês, no alfabeto latino, ocorre uma única vez em quatro textos. No arquivo ruPP005, refere-se à denominação de uma empresa.

Atualmente, esse é um dos meios populares de neutralização em massa da acidez do papel, proposto pela empresa Preservation Technologies. As partículas de óxido de magnésio $(\mathrm{MgO})$ em suspensão no solvente orgânico perfluoroheptano servem de agente neutralizador. (ruPP005, tradução, itálico e sublinhado nossos) ${ }^{18}$

Os outros três textos em que aparece preservation são: ruPP002 (resumo expandido da dissertação “A diversidade da conservação nas coleções de livros manuscritos no acervo da biblioteca científica”); ruPP030 (dissertação citada na página 10); ruPP061 (resumo expandido da dissertação “A conservação preventiva como orientação promissora para garantia do estado de conservação dos acervos de bibliotecas científicas”). Em todos os três, a ocorrência do termo em inglês acontece na seção que discute aspectos terminológicos.

No ruPP002, “Em resultado da análise terminológica, observou-se na teoria nacional [russa] a existência de uma lacuna que, na prática ocidental, é preenchida pelo termo preservation”. (destaque do original $)^{19}$

\footnotetext{
${ }^{16}$ Словарь иностранных слов русского языка. Disponível em:

https: / /dic.academic.ru/contents.nsf/dic_fwords/

17 Исторический словарь галлицизмов русского языка. Disponível em: https://gallicismes.academic.ru/

18 Em russo: В настоящее время это один из популярных способов массовой нейтрализации кислотности бумаги, предложенный компанией Preservation Technologies. Нейтрализующим агентом служат частицы оксида магния MgO, взвешенные в органическом растворителе перфторгептане.

19 Em russo: В результате терминологического анализа в отечественной теории обозначается существование лакуны, которая в западной практике заполнена термином preservation.
}

TradTerm, São Paulo, v.36, dezembro/2020, p. 102-127 www.revistas.usp.br/tradterm 
No ruPP030, o termo em inglês aparece em um contexto de crítica do instrumento normativo federal GOST 7.48.2002. Questiona o fato de terem listado os termos da área e não terem incluído dokument [documento], uma vez que ele é recorrente em unidades como sokhrannosti dokumenta [estado de conservação do documento], regim khranenia dokumenta [regime de guarda do documento] e restavratsia dokumenta [restauração do documento]. Além disso, apontam a ausência do termo em inglês preservation.

Em segundo lugar, falta o termo de língua inglesa preservation. Esse é um termo de significado amplo, que abrange conservação e tudo o que se faz na biblioteca para melhorar o estado do documento. No entanto, por não terem conseguido um equivalente em russo, não se justifica desprezarem termo tão básico. Enquanto não se forja solução melhor, conviria pelo menos usar "сохранение" [sokhranenie.$^{20}$

No ruPP061, faz-se a comparação da terminologia estrangeira e da russa e aponta-se que, em fontes de outros países, encontram-se as noções de preventive conservation e de preventive preservation. Para esses termos, o autor coloca entre parênteses, respectivamente, preventivnaia konservatsia (conservação preventiva) e preventivnoe obespetchenie sokhrannosti [garantia preventiva do estado de conservação] ou preventivnaia zaschita [proteção preventiva].

No início do projeto, na lista de palavras de busca para textos em russo, não incluímos prezervatsia. E os títulos do catálogo dos textos russos não continham essa palavra. Portanto, no momento de estabelecer o equivalente em russo para "preservação", tivemos dúvidas. A partir das acepções nos dicionários russos e do contexto de preservation nos textos do corpus, selecionamos três candidatos a equivalente: sokhranenie, obespetchenie sokhranosti e zaschita. Buscamos esses candidatos no corpus e encontramos os resultados apresentados a seguir.

Quadro 8. Ocorrências de candidatos a equivalente de "preservação" no corpus de língua russa.

20 Em russo: Во-вторых, отсутствует англоязычный термин preservation. Это термин широкого значения, охватывающий и консервацию, и все, что делается в библиотеке для улучшения состояния документов. Однако из-за того, что не сумели найти русский эквивалент, выбрасывать основополагающий термин недопустимо. Пока не придумано лучшего, следовало бы оставить и «сохранение».

TradTerm, São Paulo, v.36, dezembro/2020, p. 102-127 www.revistas.usp.br/tradterm 


\begin{tabular}{|l|l|l|}
\hline Candidato a termo & Tradução & Ocorrências \\
\hline sokhranenie & $\begin{array}{l}\text { ver discussão anterior no item } \\
3.2 .1\end{array}$ & 1333 \\
\hline $\begin{array}{l}\text { obespetchenie } \\
\text { sokhrannosti }\end{array}$ & garantia do estado de conservação & 0390 \\
\hline zaschita & proteção & 0386 \\
\hline
\end{tabular}

Fonte: As autoras

O texto ruPP038, embora não contenha o termo preservation, também ajudou a esclarecer essa questão terminológica e ainda trouxe as noções de sokhrannost [estado de conservação] e khranenie [guarda, conservação, depósito].

Quando falamos em "sokhrannost" [estado de conservação] em relação a acervos de bibliotecas, sokhrannost pressupõe a presença física do documento no acervo ou nas mãos do usuário, a integridade de todas as suas partes constituintes, a sua imutabilidade e a ausência de danos. "Sokhrannost", desse modo, é uma noção mais restrita do que “хранение" [khranenie, guarda, conservação, depósito]. Ela não inclui a tecnologia de organização dos acervos, nem uma série de outros elementos. Além disso, diferentemente de khranenie e cokhranenie, ela se apresenta não como um processo, mas como um estado do acervo que resulta de sua khranenie, do controle de uma série de fatores de âmbito social e tecnológico. Particularmente, a sokhrannost é garantida pela proteção do acervo contra deterioração e depredação. Por sokhrannost compreende-se a garantia da integridade e da condição física normal dos documentos guardados no acervo. ${ }^{21}$

De acordo com os textos citados, não há em russo um equivalente para preservation. Foi feita a tentativa de preencher essa lacuna com sokhrannost, termo que acabou por se consagrar como estado (condição) de conservação e não como a ação que garante esse estado. No GOST 7.48-2002, o equivalente em inglês para sokhrannost

${ }^{21}$ Em russo: Говоря о "сохранности" в отношении библиотечных фондов, сохранность предполагает физическое наличие документа в фонде или на руках у пользователя, целость всех его составных частей, их неизменность, отсутствие повреждений. "Сохранность", таким образом, более узкое понятие, чем "хранение". Она не включает в себя технологию размещения фондов и ряд других моментов. Кроме того, она, в отличие от хранения и сохранения, представляет собой не процесс, а состояние фонда, являющееся результатом его хранения, учета ряда факторов социального и технологического свойства. В частности, сохранность обеспечивается охраной фонда от порчи и хищений. Под сохранностью понимается обеспечение целостности и нормального физического состояния документов, хранящихся в фонде. (sublinhados nossos) 
é safe keeping e a sua definição: “состояние документа, характеризуемое степенью удержания эксплуатационных свойств" [estado de conservação do documento, caracterizado pelo grau de manutenção de suas propriedades operacionais].

Dos três candidatos a equivalente de "preservação", sokhranenie é o mais produtivo no corpus. Entretanto, como equivalente para termos e UFEs eventivas em português, obespetchenie sokhrannosti aparece como variação ou também como equivalente. Por isso, na base terminológica, temos três situações.

1. O equivalente de "preservação" é sokhranenie. Exemplo: para "preservação 2", como área de estudo, ocorre no corpus apenas sokhranenie.

2. os equivalentes de "preservação" são sokhranenie e obespetchenie sokhrannosti. Exemplo: “atividade de preservação”. Деятельность по сохранению [deiatelnost po sokhraneniu], 60 ocorrências, em 11 arquivos. Деятельность по обеспечению сохранности [deiatelnost po obespetcheniu sokhrannosti], 16 ocorrências em 11 arquivos. Na base, um remete ao outro pelo campo "Ver também".

3. o equivalente de "preservação" é obespetchenie sokhrannosti. Exemplo: para "preservação de livros", ocorre no corpus apenas obespetchenie sokhrannosti knigui, 03 ocorrências em 03 textos.

\section{Conclusões}

Discutimos neste artigo questões de Terminologia e Tradução da área da Conservação de bens culturais móveis em papel nas línguas portuguesa e russa. Mostramos como, em uma pesquisa terminológica, os resultados das diversas etapas vão se acumulando e confirmando ou contradizendo as primeiras descobertas. De modo mais abrangente, em um grupo de pesquisa longevo, os projetos sequenciais permitem a acumulação de conhecimentos que são sempre revisados e revistos.

A descrição e análise da busca de equivalentes em russo para termos e UFEs eventivas em português e as soluções da tradução do catálogo de textos do corpus russo 
permitiram que a equipe de língua russa do projeto tivesse maior compreensão da terminologia da Conservação e pudesse tomar as decisões de modo mais fundamentado.

Em consonância com outros trabalhos do Termisul, constatamos a importância da Terminologia no trabalho do tradutor, sobretudo, mas não somente, no campo dos textos especializados. Reforçamos a importância da elaboração de ferramentas, nesse caso, a base terminológica multilíngue, que levam em conta situações reais de uso dos termos e, assim, possam auxiliar o tradutor a buscar soluções satisfatórias sem que ele precise se dedicar a muitas horas ou dias de pesquisa.

Podemos destacar ainda a relevância da intervenção humana na análise dos dados de pesquisas com corpora. Levando em conta o contexto, a situação de uso, pesquisas no corpus e fora dele. No estudo dos termos "preservação", "conservação" e "restauração", observamos que os equivalentes encontrados no corpus são reflexo não só do seu uso pelos especialistas, mas também do surgimento e consolidação de áreas de pesquisa e das trocas internacionais, sobretudo em órgãos vinculados a organizações como a ONU, por exemplo.

A linguagem especializada está sujeita a variações, com a presença de formas alternativas de denominação do mesmo conceito dentro de uma mesma língua e entre línguas diferentes. Essa variação, intrínseca ao processo comunicativo, pode ser observada no uso de cokhranenie e obespetchenie sokhrannosti como equivalente de "preservação".

Entre pesquisas futuras que podem nos auxiliar a compreender melhor 0 funcionamento dos textos especializados da área em português e os seus equivalentes em russo estão:

- Estudar a influência das diretrizes internacionais (de órgãos como a UNESCO, por exemplo, que fomenta atividades de conservação no mundo todo) sobre as terminologias nacionais. Para isso seria necessário analisar os documentos internacionais e as suas versões para as línguas em questão;

- Investigar diacronicamente a terminologia da área de Conservação, levando em conta o momento de surgimento dos cursos em universidades no Brasil e na Rússia e o uso dos termos nas áreas afins; 
- Na língua russa, observar e caracterizar as variações e polissemias relacionadas à preexistência de termos de origem eslava e ao uso de estrangeiros, sobretudo originários das línguas inglesa, alemã e francesa.

0 projeto que suscitou as questões de pesquisa descritas e analisadas neste artigo desdobrou-se em um projeto subsequente, atualmente em andamento, denominado "Conservação dos bens culturais móveis em papel: identificação e representação de unidades fraseológicas especializadas (UFEs) - Língua Russa”. 


\section{Referências bibliográficas}

ARcos, M. Identificação e análise de UFE eventivas na área da Conservação e restauração de Bens Culturais Móveis em suporte papel. Dissertação (Mestrado em Lexicografia, Terminologia e Tradução: Relações Textuais). Universidade Federal do Rio Grande do Sul, Porto Alegre, 2019.

BeVILACQUA, C. R. Unidades Fraseológicas Especializadas Eventivas: descripción y reglas de formación en el ámbito de la energía solar. Orientador: María Teresa Cabré. 2004. $241 \mathrm{f}$. Tese (Doutorado em Linguística Aplicada) - Instituto Universitário de Linguística Aplicada (IULA), Universidade Pompeu de Fabra, Barcelona. 2004.

BEVILACQUA, C. R.; BoJANOSKI, S. Os termos preservação, restauração, conservação e conservação preventiva de bens culturais: uma abordagem terminológica. Calidoscópio, São Leopoldo (RS), v. 15, n. 3, p. 443-454, set./dez. 2017.

BeVILACQUA, C. R.; KILIAN, C. K. "Tradução e terminologia: relações necessárias e a formação do tradutor”. Domínios da Lingu@gem. Uberlândia, v. 11, n. 5, dez. 2017, p. 1707-1726.

BoJANOSKI, S. F. Terminologia em Conservação de bens culturais em papel: produção de um glossário para profissionais em formação. Tese (doutorado em Memória Social e Patrimônio Cultural). Universidade Federal de Pelotas (UFPEL), Pelotas (RS), 2018.

CABRÉ, M. T. La terminología: representación y comunicación. Elementos para una teoría de base comunicativa y otros artículos. Barcelona: Institut Universitari de Lingüística Aplicada, 1999.

HURTADO AlBIR, A. Traducción y traductología: introducción a la traductología. Madrid: Ediciones Cátedra, 2001.

MACIEL, A. M. B.; ReUILLARD, P. C. R. "Abordagem da variação terminológica em uma base de dados de combinatórias léxicas". TradTerm, São Paulo, v. 26, dez./2015, p. 223-240. Disponível em:

<https://www.revistas.usp.br/tradterm/article/view/113393/111357>. Acesso em: 08 jun 2018.

WAQUIL, M. L. Tradução de textos especializados: Unidades Fraseológicas Especializadas e técnicas tradutórias. Dissertação (Mestrado em Lexicografia, Terminologia e Tradução). Universidade Federal do Rio Grande do Sul, Porto Alegre, 2013. 


\section{Obras lexicográficas}

UCHAKOV, D. N. (ORG.). Толковый словарь Ушакова. [Dicionário Uchakov]. 1935-1940. Disponível em: <https://dic.academic.ru/contents.nsf/ushakov/>. Acesso em: 03 dez 2020.

VoINOVA, N.; STARETS, S.; VeRKHUCHA, V.; ZdITOVETSKI, A. Dicionário russo-português. Lisboa: Ulmeiro; Moscou: Edições “Russki Yazik”, 1989.

\section{Documentos de padronização}

GOST 7.87-2003. Межгосударственный стандарт. Система стандартов по ийформации, библиотечному и издательскому делу. Книжные памятники. Общие требование. [Padrão interestatal. Sistema de padrões para serviços de informação, bibliotecas e editoras. Conservação de documentos. Livros raros. Requisitos gerais.] Disponível em: <http://docs.cntd.ru/document/1200035672>. Acesso em: 07 jan. 2017

GOST 7.50-2002. Межгосударственный стандарт. Система стандартов по ийформации, библиотечному и издательскому делу. Консервация документов. Общие требования. [Padrão interestatal. Sistema de padrões para serviços de informação, bibliotecas e editoras. Conservação de documentos. Requisitos gerais.] Disponível em: <http://docs.cntd.ru/document/1200030174/>. Acesso em: 07 jan. 2017

GOST 7.48-2002. Система стандартов по ийформации, библиотечному и издательскому делу. Консервация документов. Основные термины и определения. Межгосударственный совет по стандартизации, метрологии и сертификации. [Sistema de padrões para serviços de informação, bibliotecas e editoras. Conservação de documentos. Termos básicos e determinações. Conselho Internacional para padronização, metrologia e certificação.] Disponível em: $<$ http://docs.cntd.ru/document/1200030173 >. Acesso em: 07 jan 2017

Recebido em: 22/07/2020

Aceito em: 22/10/2020

Publicado em dezembro de 2020

TradTerm, São Paulo, v.36, dezembro/2020, p. 102-127

www. revistas.usp.br/tradterm 